\title{
Consumo, comportamento ingestivo e perfil metabólico de ovinos alimentados com ração extrusada com diferentes relações volumoso: concentrado
}

\author{
Paulo Arthur Cardoso Ruela ${ }^{1}$; Karla Alves Oliveira ${ }^{2}$; Luciana Melo Sousa ${ }^{3 *}$; Simone Pedro da Silva ${ }^{4}$; Luciano \\ Fernandes Sousa ${ }^{5}$; Gilberto de Lima Macedo Júnior ${ }^{6}$
}

DOI: https://doi.org/10.35699/2447-6218.2020.20412

\begin{abstract}
Resumo
Objetivou-se avaliar o efeito da utilização de ração extrusada com diferentes relações volumoso:concentrado (V:C) sob o consumo, comportamento ingestivo e parâmetros sanguíneos em ovinos. Foram utilizados cinco machos $1 / 2$ Dorper e $1 / 2$ Santa Inês, não castrados, com peso corporal médio de 34,5 $\pm 4,10 \mathrm{~kg}$ e idade média de sete meses. O delineamento experimental utilizado foi o Quadrado Latino $5 \times 5$. Os tratamentos utilizados foram diferentes relações V:C (\%) de ração extrusada, sendo as seguintes 30:70, 40:60, 50:50, 60:40 e 70:30. As variáveis mensuradas foram consumo de matéria seca (CMS), tempo em ingestão, ruminação, ócio e mastigação e as relações destes com o CMS dos animais. Os metabólitos energéticos e hepáticos analisados foram frutosamina, colesterol total, triglicerídeos, lipoproteína de baixíssima densidade (VLDL), fosfatase alcalina, gama-glutamiltransferase e aspartato-aminotransferase. Os metabólitos proteicos e minerais analisados foram ureia, ácido úrico, albumina, creatinina, proteínas totais, cálcio, fósforo e magnésio. Não houve efeito da utilização da ração extrusada nas diferentes relações V:C sobre a concentração dos metabólitos estudados, com exceção do ácido úrico. Também não se verificou efeito sobre CMS e comportamento ingestivo. Conclui-se que ovinos alimentados com ração extrusada nas relações V:C estudadas conseguem manter estável o metabolismo energético, proteico e mineral sem desenvolvimento de problemas no fígado e rins.
\end{abstract}

Palavras-chave: Nutrição. Ruminantes. Metabolismo. Ovis aries.

\section{Intake, feeding behavior and metabolic profile of sheep fed extruded ration with different roughage: concentrate ratios}

\author{
Abstract

\footnotetext{
${ }^{1}$ Universidade Federal de Uberlândia. Uberlândia, MG. Brasil.

https://orcid.org/0000-0001-9136-3920

${ }^{2}$ Universidade Estadual Paulista Júlio de Mesquita Filho. Jaboticabal, SP. Brasil.

https://orcid.org/0000-0002-7792-2615

${ }^{3}$ Universidade Estadual Paulista Júlio de Mesquita Filho. Jaboticabal, SP. Brasil.

https://orcid.org/0000-0003-1016-8248

${ }^{4}$ Universidade Federal de Uberlândia. Uberlândia, MG. Brasil.

https://orcid.org/0000-0002-6391-1122

${ }^{5}$ Universidade Federal do Tocantins. Araguaína, TO. Brasil.

https://orcid.org/0000-0002-6072-9237

${ }^{6}$ Universidade Federal de Uberlândia. Uberlândia, MG. Brasil.

https://orcid.org/0000-0001-5781-7917

*Autor para correspondência: lumelosousa@gmail.com
}

The objective was to evaluate the effect of feeding extruded ration with different roughage: concentrate (R:C) ratios on consumption, ingestive behavior and blood parameters on sheep. Five $1 / 2$ Dorper and $1 / 2$ Santa Inês males, uncastrated, with an average body weight of $34.5 \pm 4.10 \mathrm{~kg}$ and an average age of seven months were used. The experimental design used was the Latin Square 5x5. The treatments used were different R:C ratios (\%) of extruded ration, witch were 30:70, 40:60, 50:50, 60:40 and 70:30. The assessed variables were dry matter intake (DMI), intake time, rumination, idleness, chewing and their relationship with the DMI of animals. The energetic and hepatic metabolites

Recebido para publicação em 02 de Maio de 2020. Aceito para publicação 25 de Outubro de 2020.

e-ISSN: 2447-6218 / ISSN: 2447-6218. Atribuição CC BY. 
Ruela, P. A. C. et al.

analyzed were fructosamine, total cholesterol, triglycerides, very low density lipoprotein (VLDL), alkaline phosphatase, gamma-glutamyltransferase and aspartate-aminotransferase. The protein and mineral metabolites analyzed were urea, uric acid, albumin, creatinine, total proteins, calcium, phosphorus and magnesium. There was no effect on feeding extruded ration with different $\mathrm{R}: \mathrm{C}$ ratios on the concentration of metabolites, except for uric acid. There was also no effect on DMI and ingestive behavior. It is concluded that sheep fed with extruded ration in the studied R:C ratios are able to keep energy, protein and mineral metabolism stable without developing liver and kidney problems.

Key-words: Nutrition. Metabolism. Ovis aries. Ruminants.

\section{Introdução}

A busca por eficiência nos sistemas de produção de ovinos tem culminado no aperfeiçoamento de várias práticas de manejo, como raças mais produtivas e melhorias nos aspectos nutricionais visando a aumentar a produtividade. No entanto, os índices produtivos desses rebanhos ainda são considerados baixos, o que está associado, principalmente, ao manejo nutricional inadequado (Santos et al., 2011). Nesse sentido, a utilização de processamentos aplicados ao alimento com o objetivo de melhorar o aproveitamento dos nutrientes é de grande importância. Diversos tratamentos podem ser aplicados no volumoso ou concentrados, no sentido de melhorar a digestibilidade dos nutrientes, como por exemplo, a extrusão, que consiste em aplicar alta temperatura $\left(130\right.$ a $\left.150^{\circ} \mathrm{C}\right)$, pressão (30 a $\left.60 \mathrm{~atm}\right)$ e umidade no alimento, o que promove expansão dos ingredientes da ração (Vieira et al., 2005), gelatinização do amido, desnaturação da proteína (Salman, 2008) e redução de fatores antinutricionais.

Um dos principais fatores que influencia o consumo em ruminantes é a relação volumoso:concentrado da dieta. $\mathrm{O}$ fornecimento de dieta muito fibrosa pode diminuir a digestibilidade, reduzindo assim o consumo e ganho de peso, em função do alto conteúdo de celulose e baixo valor nutritivo, o que não atende as necessidades de nutrientes para mantença dos animais (Beigh et al., 2017). O uso de dietas ricas em concentrados pode ter efeitos negativos sobre a fermentação ruminal e ocasionar distúrbios metabólicos nos animais (Oetzel, 2017). No entanto, pouco se conhece sobre o uso de diferentes relações volumoso:concentrado na dieta quando esses alimentos são extrusados, devido a possibilidade desse processamento alterar a digestibilidade e consumo dos nutrientes, bem como o comportamento ingestivo e parâmetros metabólicos.

Oliveira et al. (2018) avaliaram duas dietas, uma com $100 \%$ de silagem de milho e outra com $100 \%$ de volumoso extrusado (Foragge ${ }^{\circledR}$ ) e verificaram que ovinos alimentados com volumoso extrusado em substituição à silagem de milho apresentaram melhorias nos parâmetros nutricionais, como aumento no consumo e digestibilidade da matéria seca, redução no tempo em mastigação e ruminação sem ocasionar disfunções no metabolismo energético e proteico. No entanto, não se conhece quais níveis de inclusão de volumoso e concentrado extrusado podem ser utilizados na dieta de ovinos para melhorar os parâmetros nutricionais sem promover disfunções metabólicas.

Com o desenvolvimento de tecnologia no manejo alimentar e surgimento de novos alimentos processados, a avaliação do consumo, comportamento ingestivo, bem como do perfil metabólico são necessários para entendimento das vantagens e desvantagens do uso dos alimentos extrusados. Portanto, é importante determinar quais níveis de inclusão desses alimentos irão otimizar os parâmetros nutricionais. Objetivou-se avaliar o efeito da utilização de ração extrusada com diferentes relações volumoso:concentrado (V:C) sobre o consumo, comportamento ingestivo e parâmetros sanguíneos em ovinos.

\section{Material e métodos}

O experimento foi realizado na Fazenda Experimental Capim Branco da Universidade Federal de Uberlândia, no município de Uberlândia - MG, com latitude 1852'41" S e longitude 4820'38" W. O experimento foi aprovado pelo Comitê de Ética na utilização de animais (CEUA) sob protocolo $n^{\circ} 140 / 16$, e foi realizado nos meses de julho a setembro de 2015 , com duração de 75 dias, sendo dividido em cinco períodos de 15 dias, dos quais dez dias foram utilizados para adaptação dos animais aos tratamentos e cinco dias para coleta de dados. Foram utilizados cinco ovinos machos $1 / 2$ Dorper e $1 / 2$ Santa Inês, não castrados, com peso corporal médio de $34,5 \pm 4,10$ $\mathrm{kg}$ e idade média de sete meses, que foram alojados em gaiolas metabólicas, com dispositivos para coleta de fezes e urina, durante todo o período experimental. O fornecimento da ração foi feito duas vezes ao dia (08:00 e 15:30). As sobras foram coletadas diariamente e foram feitos ajustes diários no fornecimento da dieta de forma a permitir $10 \%$ de sobras.

A ração era composta por dois tipos de pellets, sendo um de concentrado (Beef Total ${ }^{\circledR}$, Nutratta, Brasil) e outro de volumoso (Nutratta Foragge ${ }^{\circledR}$, Nutratta, Brasil). $\mathrm{O}$ produto veio misturada pelo fabricante em único produto, contendo os dois pellets, sendo formulado de forma a atender as relações $\mathrm{V}: \mathrm{C}$ testadas no presente estudo. Contudo, no momento do fornecimento aos animais, foi realizada nova homogeneização para evitar discrepâncias no arraçoamento. Os animais tinham acesso ad libitum 
Consumo, comportamento ingestivo e perfil metabólico de ovinos alimentados com ração extrusada com diferentes relações volumoso: concentrado

à água e recebiam sal mineral, cujos recipientes ficaram anexos lateralmente às gaiolas metabólicas.

Os tratamentos utilizados no experimento foram a ração total extrusada descrita anteriormente em diferentes proporções de volumoso e concentrado $(\mathrm{V}: \mathrm{C})$, sendo as seguintes: 30:70; 40:60; 50:50; 60:40 e 70:30, expressas na matéria seca. A composição químico-bromatológica da ração extrusada fornecida aos animais está apresentada na Tabela 1.

Tabela 1 - Composição química-bromatológica das dietas com diferentes relações volumoso: concentrado.

\begin{tabular}{cccccc}
\hline Nutrientes (\%MS) & \multicolumn{5}{c}{ Relação Volumoso:Concentrado (V:C) } \\
\hline & 30 V: $70 \mathrm{C}$ & 40 V: $60 \mathrm{C}$ & $50 \mathrm{~V}: 50 \mathrm{C}$ & $60 \mathrm{~V}: 40 \mathrm{C}$ & 70 V: $30 \mathrm{C}$ \\
MS & 93,72 & 92,14 & 94,55 & 94,65 & 95,38 \\
PB & 16,07 & 15,17 & 14,29 & 13,38 & 12,50 \\
FDN & 18,73 & 20,68 & 22,61 & 24,53 & 26,46 \\
FDA & 12,31 & 13,56 & 14,76 & 16,02 & 17,27 \\
MM & 5,98 & 6,06 & 6,14 & 6,21 & 6,29 \\
CNF & 57,76 & 56,63 & 55,50 & 54,37 & 53,26 \\
NDT & 77,73 & 76,29 & 75,47 & 74,65 & 73,81 \\
EE & 2,05 & 2,04 & 2,04 & 2,03 & 2,02 \\
\hline
\end{tabular}

MS - matéria seca; FDN - fibra insolúvel em detergente neutro; FDA fibra insolúvel em detergente ácido; MM matéria mineral; CNF - carboidratos não fibrosos; NDT - nutrientes digestíveis totais; EE - extrato etéreo.

Para determinação do consumo de matéria seca (CMS), foi realizada a pesagem individual do alimento fornecido e das sobras, sendo o consumo obtido por diferença. Nas amostras dos ingredientes da ração e das sobras foram determinados os teores de matéria seca por secagem em estufa a $105^{\circ} \mathrm{C}$ por $24 \mathrm{~h}$ (Association of Oficial Analytical Chemists - AOAC, 1995). O CMS foi expresso em kg.dia ${ }^{-1}$, em relação ao peso corporal (\%PC) e peso metabólico $\left(\mathrm{PC}^{0.75}\right)$.

A avaliação do comportamento ingestivo dos animais foi feita no último dia de cada período experimental. Os animais foram observados a cada cinco minutos durante 24 horas, por avaliadores treinados para não causar nenhum tipo de perturbação aos animais, e foi identificado se os animais se encontravam em ingestão, ruminação ou ócio, em que ócio se caracteriza por ausência de movimentos mandibulares, de acordo com Johnson e Combs (1991). O tempo em mastigação foi calculado pela soma da ingestão e da ruminação como citado por Bürger et al. (2000) e Bal e Büyükünal Bal (2010). No período noturno, as luzes ficaram sempre acessas, durante todo o período experimental, para não causar qualquer tipo de alteração nas avaliações do comportamento ingestivo dos animais.

Para determinação dos metabólitos sanguíneos, foram realizadas coletas de sangue no primeiro e último dia de cada período experimental (para análise estatística foi considerada a média desses dois dias), antes da primeira alimentação, através de venopunção jugular com auxílio de Vacuntainer ${ }^{\circledR}$ acoplado a tubo sem anticoagulante. Logo após a colheita do sangue, as amostras foram processadas em analisador semiautomático (espectrofotômetro) Bioplus ${ }^{\circledR} 2000$.

Os metabólitos energéticos analisados foram frutosamina, colesterol total, triglicerídeos, lipoproteína de baixíssima densidade (VLDL) e os metabólitos hepáticos foram fosfatase alcalina (FA), gama-glutamiltransferase (GGT) e aspartato-aminotransferase (AST). Os metabólitos proteicos avaliados foram proteínas totais, ureia, ácido úrico, creatinina e albumina, enquanto os metabólitos minerais avaliados foram magnésio, cálcio e fósforo. Para determinação dos metabólitos utilizou-se Kits comerciais da LabTest ${ }^{\circledR}$ (específico para cada metabólito) com aparelho automático PKL $\left(\mathrm{MHLab}^{\circledR}\right)$

O delineamento experimental adotado foi o Quadrado Latino 5x5, sendo cinco os tratamentos (relação volumo:concentrado) e períodos. Cada tratamento com cinco repetições. Os dados foram submetidos aos testes de normalidade (Shapiro e Wilk, 1965) e homocedasticidade (Cochran, 1941). As variáveis normais e com variâncias homogêneas foram submetidas a análise de regressão observando-se a significância dos efeitos linear, quadrático e não significância da falta de ajuste do modelo, sendo a significância utilizada para tomada de decisão 5\% de probabilidade de erro tipo I. Utilizou-se o pacote estatístico Statistical Analysis System - SAS (2012). Os efeitos de animais e períodos foram considerados nos modelos de regressão, mas somente os valores do fator regressor foram usados na obtenção dos coeficientes. Apesar da estimativa do erro experimental (variância experimental) ser obtida com base em todos os elementos do modelo o efeito linear e quadrático se referem aos coeficientes 
Ruela, P. A. C. et al.

únicos relacionados. A variável explicativa foi o percentual de volumoso.

\section{Resultados e discussão}

Não houve efeito da utilização da ração extrusada nas diferentes relações $\mathrm{V}: \mathrm{C}$ sobre o consumo de matéria seca (CMS) e em relação ao peso corporal (\%PC; $\mathrm{P}>0,05$; Tabela 2). Os animais do presente estudo apresentaram CMS médio de 1,63 kg.dia ${ }^{-1}$. O CMS médio expresso em relação ao peso corporal ficou acima do proposto pelo National Research Council - NRC (2007) para ovinos nesta categoria (3,4\% do PC). O maior CMS obtido nos animais do presente estudo ocorreu em consequência da maior facilidade de apreensão e ingestão da ração extrusada. O processo de extrusão promove redução no tamanho da partícula (TP) do alimento, ocasionando aumento na taxa de passagem e no consumo (Seo et al., 2009; Moharrery, 2010). Oliveira et al. (2018) verificaram, maior CMS expresso em kg.dia ${ }^{-1}$, em relação ao peso corporal (\%PC) e peso metabólico $\left(\mathrm{PC}^{0,75}\right)$ em ovinos alimentados com volumoso extrusado em comparação à silagem de milho.

As diferentes relações V:C não comprometeram o tempo gasto em ingestão, ruminação e mastigação ( $\mathrm{P}>0,05$; Tabela 2), provavelmente em decorrência da ausência de efeito dos tratamentos sobre o CMS e possível seleção de alimentos realizada por ovinos, uma maneira de compensarem a reduzida capacidade fermentativa. Quando permitido, esses animais escolhem partes da forrageira que são mais nutritivas, como caules, folhas e brotos de boa qualidade, realizando maior seleção por apresentarem focinho estreito e alta mobilidade de língua e lábios (Tedeschi et al., 2019). Nesse sentido, os ovinos podem ter selecionado a favor do concentrado ou do volumoso, disponibilizados em dois tipos de pellets, não permitindo identificar diferenças da relação volumoso:concentrado sobre as variáveis do comportamento ingestivo.

Tabela 2 - Efeito da utilização de ração extrusada em diferentes relações V:C sobre o consumo de matéria seca e comportamento ingestivo de ovinos.

\begin{tabular}{|c|c|c|c|c|c|c|c|c|c|}
\hline & \multicolumn{5}{|c|}{ Tratamentos } & \multirow{2}{*}{ MG } & \multirow{2}{*}{$\mathrm{CV}$} & \multirow{2}{*}{$\begin{array}{c}\text { Valor } P \\
\text { (L) }\end{array}$} & \multirow{2}{*}{$\begin{array}{c}\text { Valor } P \\
\text { (Q) }\end{array}$} \\
\hline & 30V:70C & 40V:60C & 50V:50C & $60 \mathrm{~V}: 40 \mathrm{C}$ & $70 \mathrm{~V}: 30 \mathrm{C}$ & & & & \\
\hline CMS $\left(\mathrm{kg} \cdot \mathrm{dia}^{-1}\right)$ & 1,50 & 1,59 & 1,66 & 1,66 & 1,73 & 1,63 & 17,26 & 0,369 & 0,387 \\
\hline CMSPC (\%) & 3,36 & 3,44 & 3,70 & 3,86 & 3,86 & 3,64 & 17,83 & 0,389 & 0,421 \\
\hline CMSPM(g.kg-0,75) & 44,53 & 44,37 & 44,99 & 45,45 & 44,56 & 44,78 & 3,41 & 0,378 & 0,472 \\
\hline Ing. (min.dia-1) & 240,0 & 173,0 & 240,0 & 230,0 & 257,0 & 228,0 & 25,03 & 0,589 & 0,258 \\
\hline Ócio (min.dia-1) & 919,0 & 958,0 & 866,0 & 965,0 & 858,0 & 913,2 & 8,62 & 0,679 & 0,367 \\
\hline Rum. (min.dia-1) & 281,0 & 309,0 & 334,0 & 245,0 & 325,0 & 298,80 & 26,34 & 0,237 & 0,521 \\
\hline Mast. (min.dia ${ }^{-1}$ ) & 521,0 & 482,0 & 574,0 & 475,0 & 582,0 & 526,8 & 14,94 & 0,448 & 0,896 \\
\hline CMS/Ing.(g.min-1) & 7,30 & 10,41 & 7,37 & 7,03 & 6,71 & 7,76 & 32,21 & 0,748 & 0,889 \\
\hline CMS/Rum(g.min $\left.{ }^{-1}\right)$ & 5,99 & 5,47 & 5,47 & 6,92 & 5,13 & 5,80 & 36,07 & 0,759 & 0,796 \\
\hline CMS/Mast(g.min $\left.{ }^{-1}\right)$ & 3,20 & 3,44 & 3,10 & 3,34 & 2,82 & 3,18 & 18,24 & 0,874 & 0,712 \\
\hline
\end{tabular}

CMS - Consumo de matéria seca; CMSPC - CMS em relação ao peso corporal; CMSPM - CMS em relação ao peso metabólico; Ing - ingestão; Rum ruminação; Mast - mastigação; CMS/ing - relação entre CMS e Ing; CMS/Rum - relação entre CMS e Rum; CMS/Mast - relação entre CMS e Mast; MG - média geral; CV - coeficiente de variação;

O tempo gasto em alimentação e ruminação por ovinos recebendo rações não extrusada são maiores devido à forma física do alimento, visto que os animais gastam mais tempo no processo de apreensão, como também manipulando o alimento na boca para realizar a deglutição. De fato, no presente estudo, os animais recebendo a relação $\mathrm{V}: \mathrm{C}(60: 40)$ apresentaram tempo em

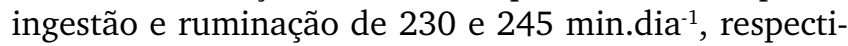
vamente. Figueiredo et al. (2013) verificaram os tempos em ingestão e ruminação por ovinos recebendo ração não extrusada na mesma proporção V:C de 60:40 e relataram 260 e 515 min.dia ${ }^{-1}$, respectivamente. O menor tempo em ingestão e ruminação nos animais alimentados com ração extrusada acontece pela redução do tamanho de partícula do alimento, que resulta em menor efetividade da fibra. O comprimento do volumoso extrusado era de aproximadamente $2 \mathrm{~mm}$. Gomes et al. (2012) relataram redução no tempo em ruminação em consequência do menor tamanho de partícula do volumoso. Correlação positiva significativa foi verificada entre porcentagem de FDN fisicamente efetivo da dieta e tempo em ruminação nos trabalhos conduzidos por Byskov et al. (2015) e White et al. (2017). Em estudo conduzido por Oliveira et al. (2018), ovinos recebendo volumoso extrusado apresentaram menor tempo de ruminação e mastigação total e, 
consequentemente, maior tempo em ócio quando comparados aos animais alimentados com silagem de milho.

Não houve alteração no metabolismo energético e hepáticos dos ovinos alimentados com ração extrusada nas diferentes relações V:C (P>0,05; Tabela 3). As concentrações séricas de colesterol, triglicerídeos, VLDL e frutosamina ficaram dentro da faixa de referência preconizados por Silva et al. (2020). Em relação a estes resultados obtidos, infere-se que os animais conseguiram manter estável o metabolismo energético, favorecendo o desempenho.

Não houve efeito da utilização de ração extrusada em diferentes relações V:C na alimentação de ovinos ( $P>0,05$; Tabela 3) sobre as enzimas hepáticas fosfatase alcalina (FA), gama-glutamiltransferase (GGT) e aspartato-aminotransferase (AST) e as mensurações destas enzimas encontram-se dentro dos valores de referência (Silva et al., 2020).

Tabela 3 - Efeito da utilização de ração extrusada nas diferentes relações V:C sobre a concentração sanguínea dos metabólitos energéticos e hepáticos em ovinos.

\begin{tabular}{|c|c|c|c|c|c|c|c|c|c|c|}
\hline & \multicolumn{5}{|c|}{ Tratamentos } & \multirow{2}{*}{ MG } & \multirow{2}{*}{$\mathrm{CV}$} & \multirow{2}{*}{$\mathrm{VR}^{1}$} & \multirow{2}{*}{$\begin{array}{l}\text { Valor } \\
\text { P (L) }\end{array}$} & \multirow{2}{*}{$\begin{array}{c}\text { Valor } P \\
\text { (Q) }\end{array}$} \\
\hline & $30 \mathrm{~V}: 70 \mathrm{C}$ & $40 \mathrm{~V}: 60 \mathrm{C}$ & $50 \mathrm{~V}: 50 \mathrm{C}$ & $60 \mathrm{~V}: 40 \mathrm{C}$ & $70 \mathrm{~V}: 30 \mathrm{C}$ & & & & & \\
\hline $\begin{array}{l}\text { Frutos. } \\
\left(\mathrm{mg} \mathrm{dL}^{-1}\right)\end{array}$ & 241,90 & 244,50 & 245,10 & 247,90 & 250,40 & 245,96 & 3,27 & 119 a 451 & 0,985 & 0,856 \\
\hline $\begin{array}{l}\text { Colest. } \\
\left(\mathrm{mg} \mathrm{dL}^{-1}\right)\end{array}$ & 43,40 & 39,90 & 42,50 & 41,20 & 38,40 & 41,08 & 32,99 & 14 a 126 & 0,589 & 0,632 \\
\hline $\begin{array}{l}\text { Trigl. (mg. } \\
\qquad \mathrm{dL}^{-1} \text { ) }\end{array}$ & 21,70 & 19,10 & 18,30 & 19,20 & 21,90 & 20,04 & 24,92 & 5 a 71 & 0,698 & 0,489 \\
\hline $\begin{array}{l}\text { VLDL (mg. } \\
\qquad \mathrm{dL}^{-1} \text { ) }\end{array}$ & 4,34 & 3,82 & 3,66 & 3,84 & 4,38 & 4,00 & 24,92 & 1 a 16,4 & 0,369 & 0,256 \\
\hline $\begin{array}{c}\text { FA } \\
(\mathrm{U} / \mathrm{L})\end{array}$ & 104,10 & 107,50 & 104,40 & 100,30 & 117,10 & 106,68 & 22,78 & 68 a 387 & 0,225 & 0,421 \\
\hline $\begin{array}{l}\text { GGT } \\
(\mathrm{U} / \mathrm{L})\end{array}$ & 60,70 & 74,00 & 73,80 & 78,50 & 71,70 & 71,74 & 32,46 & 25 a 146 & 0,478 & 0,758 \\
\hline $\begin{array}{c}\text { AST } \\
\left(\mu \mathrm{g} \cdot \mathrm{dL}^{-1}\right)\end{array}$ & 118,60 & 125,10 & 127,10 & 107,20 & 81,40 & 111,8 & 35,59 & 41 a 298 & 0,891 & 0,888 \\
\hline
\end{tabular}

*Ração extrusada em diferentes relações volumoso:concentrado. Frutos - frutosamina; Colest. - colesterol; Trigl. - triglicerídeos; VLDL - lipoproteínas de baixíssima densidade; FA - fosfatase alcalina; GGT - gama-glutamiltransferase; AST - aspartato-aminotransferase; MG - média geral; $\mathrm{CV}$ - coeficiente de variação; ${ }^{1} \mathrm{VR}=$ Valores de referência segundo Silva et al. (2020);

A medida da enzima aspartato-aminotransferase (AST) é utilizada para indicar algum tipo de lesão hepato-celular secundária oriunda de mobilização lipídica excessiva (Santos et al., 2015), quando encontrada em altas quantidades. A fosfatase alcalina (FA) é uma enzima com alta atividade em células do fígado, ossos, rins e mucosa intestinal e, assim como a enzima AST, alta atividade é indicativa de danos no fígado. No presente trabalho, as enzimas AST e FA ficaram dentro da faixa proposta por Silva et al. (2020) para a espécie ovina, o que nos leva a concluir que a utilização de ração extrusada nas diferentes relações V:C não ocasionou problemas no fígado dos animais.

A enzima gama-glutamiltransferase (GGT) é amplamente encontrada em ovinos, caprinos, bovinos e equinos e a alta quantidade dessa enzima no sangue pode indicar desenvolvimento de colestase ou lesão hepática generalizada (Kaneko et al., 2008). No presente experimento, a GGT encontra-se dentro dos valores de referência, como as enzimas AST e FA. Apesar da uti- lização de níveis mais altos de concentrado, como nas dietas com inclusão de 70 e 60\%, não foram verificadas alterações no perfil das enzimas hepáticas, o que pode ser um indicativo da não ocorrência de acidose ruminal subaguda (SARA; Kleen et al., 2003). Essa síndrome compromete o equilíbrio ácido-básico e o funcionamento dos órgãos, como fígado (Dokovic e Jasovic, 2010).

As concentrações dos metabólitos minerais não foram alteradas com a utilização da ração extrusada nas diferentes relações V:C (Tabela 4). A faixa de variação do magnésio proposta por Varanis (2018) é 1,07 a 4,66 $\mathrm{mg} . \mathrm{dL}^{-1}$, e a média encontrada neste experimento foi de $3,11 \mathrm{mg} \cdot \mathrm{dL}^{-1}$, ficando dentro do valor preconizado. Não existe controle homeostático para este mineral, sendo a concentração sanguínea resposta direta da quantidade ingerida via dieta. O magnésio é mais disponível em concentrados e forragens secas (González e Scheffer, 2003).

A concentração de cálcio média foi $7,86 \mathrm{mg} \cdot \mathrm{dL}^{-1}$, ficando dentro da faixa de referência (4,6 a 14,22 mg.dL ${ }^{-1}$; 
Ruela, P. A. C. et al.

Varanis, 2018). Cerca de 45\% do cálcio presente no sangue está associado a moléculas orgânicas, principalmente à albumina, de forma que os níveis sanguíneos de cálcio estão diretamente relacionados aos de albumina (Tabela 4). Dietas com maior teor de concentrado apresentam maior porcentagem de proteína bruta, o que poderia ter causado aumento nos níveis de cálcio, mas isso não ocorreu.

O fósforo é variável devido à reciclagem pela saliva e absorção no rúmen e intestino, mas mesmo as- sim ficou dentro dos valores de referência proposto por Varanis (2018). Dietas com altas inclusões de cereais possuem alto teor de fósforo, ao contrário de dietas com predominância de pastagens (González e Scheffer, 2003). Mesmo com o aumento na inclusão de concentrado, os animais foram capazes de se adaptar e compensar as mudanças nas relações entre Ca:P. As concentrações dos metabólitos minerais obtidos no presente estudo não sofreram alterações em função das diferentes relações $\mathrm{V}: \mathrm{C}$.

Tabela 4 - Efeito da utilização de ração extrusada em diferentes relações V:C sobre a concentração sanguínea dos metabólitos proteicos e minerais em ovinos mestiços.

\begin{tabular}{|c|c|c|c|c|c|c|c|c|c|c|}
\hline & \multicolumn{5}{|c|}{ Tratamentos } & \multirow{2}{*}{ MG } & \multirow{2}{*}{ CV } & \multirow{2}{*}{$\mathrm{VR}^{1}$} & \multirow{2}{*}{$\begin{array}{l}\text { Valor P } \\
\text { (L) }\end{array}$} & \multirow{2}{*}{$\begin{array}{c}\text { Valor } \mathrm{F} \\
\text { (Q) }\end{array}$} \\
\hline & 30V:70C & 40V:60C & $50 \mathrm{~V}: 50 \mathrm{C}$ & $60 \mathrm{~V}: 40 \mathrm{C}$ & 70V:30C & & & & & \\
\hline $\begin{array}{c}\text { Ureia } \\
\left(\mathrm{mg}^{\left.-\mathrm{dL}^{-1}\right)}\right.\end{array}$ & 30,47 & 28,31 & 23,42 & 30,59 & 28,38 & 28,23 & 34,67 & 10 a 92 & 0,325 & 0,625 \\
\hline 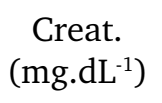 & 1,17 & 1,02 & 1,12 & 1,20 & 1,12 & 1,12 & 21,26 & 0,4 a 1,7 & 0,745 & 0,560 \\
\hline $\begin{array}{l}\text { Album. } \\
\text { (g.dL }{ }^{-1} \text { ) }\end{array}$ & 2,23 & 2,12 & 2,22 & 2,17 & 2,20 & 2,19 & 9,50 & 1,1 a 5,2 & 0,897 & 0,326 \\
\hline $\begin{array}{l}\text { Prot. T. } \\
\text { (g.dL }{ }^{-1} \text { ) }\end{array}$ & 5,68 & 5,51 & 5,30 & 5,65 & 5,77 & 5,58 & 4,50 & 3,1 a 10,7 & 0,921 & 0,951 \\
\hline $\begin{array}{c}\mathrm{AU}(\mathrm{mg} . \\
\left.\mathrm{dL}^{-1}\right)\end{array}$ & 0,47 & 0,51 & 0,42 & 0,54 & 0,79 & 0,54 & 32,97 & 0 a 1,7 & 0,258 & 0,045 \\
\hline $\begin{array}{c}\mathrm{Ca}(\mathrm{mg} . \\
\left.\mathrm{dL}^{-1}\right)\end{array}$ & 8,03 & 8,22 & 7,54 & 7,88 & 7,63 & 7,86 & 15,94 & 4,6 a $14,22^{*}$ & 0,879 & 0,702 \\
\hline $\begin{array}{l}\mathrm{P}(\mathrm{mg} . \\
\left.\mathrm{dL}^{-1}\right)\end{array}$ & 6,24 & 6,05 & 5,21 & 5,58 & 6,35 & 5,88 & 18,54 & 4,21 a $16,6^{*}$ & 0,888 & 0,792 \\
\hline$\underset{\left.\mathrm{dL}^{-1}\right)}{\mathrm{Mg}}$ & 3,42 & 3,20 & 3,11 & 2,79 & 3,06 & 3,11 & 16,77 & 1,07 a $4,66^{*}$ & 0,978 & 0,885 \\
\hline
\end{tabular}

Creat - creatinina; Album - albumina; Prot. T. - proteínas totais; AU - ácido úrico; Ca - cálcio; P - fósforo; Mg - magnésio; MG - média geral; CV - coeficiente de variação; ${ }^{1} \mathrm{VR}$ = Valores de referência segundo Silva et al. (2020); *Valores de referência segundo Varanis (2018);

Não houve efeito da utilização da ração extrusada nas diferentes relações V:C sobre a concentração dos metabólitos proteicos ( $\mathrm{P}>0,05$; Tabela 4$)$. A concentração média de proteínas totais encontrada no presente estudo foi 5,58 g.dL ${ }^{-1}$, estando dentro dos valores de referência propostos por Silva et al. (2020).

A concentração média de ureia e creatinina sanguínea ficaram dentro dos valores propostos por Silva et al. (2020). A quantidade de creatinina produzida no organismo animal é relativamente constante, sendo pouco comprometida pela alimentação (Kaneko et al., 2008). Além disso, alta concentração de creatinina sanguínea pode significar algum dano ou alteração no funcionamento dos rins, não ocorrido neste trabalho, indicando que a ração extrusada nas diferentes relações V:C não ocasionou alterações nos rins dos animais.
No presente trabalho, a concentração de albumina sérica ficou dentro dos valores de referência (Silva et al., 2020), não apresentando problemas no fígado e rins dos animais quando alimentados com a ração extrusada em diferentes relações $\mathrm{V}: \mathrm{C}$. A albumina é uma proteína sérica que regula a pressão osmótica coloidal do sangue e funciona como importante transportador de substâncias, como ácidos graxos livres, ácidos biliares, bilirrubina, cátions, alguns fármacos e minerais como ferro, cobre, cobalto, manganês e zinco (Dukes, 2006). Concentrações muito baixas de albumina podem indicar danos severos ao fígado ou aos rins.

Observa-se que, apesar de não apresentar efeito significativo, as concentrações de ureia tiveram resposta numérica contrária à do ácido úrico. Quanto maior a concentração de ácido úrico, maior é a síntese de proteína microbiana e, consequentemente, ocorre melhor 
utilização da amônia no ambiente ruminal, reduzindo o escape da mesma e promovendo queda nas concentrações plasmáticas e renal deste metabólito. Esta melhor utilização ocorreu quando os animais foram alimentados com maiores níveis de volumoso, indicando melhor sincronismo na degradação de carboidratos e proteínas. Os derivados de purina são comumente utilizados para estimar a produção de proteína microbiana (Saeed et al., 2018). Alguns trabalhos confirmaram a relação entre produção de proteína microbiana e excreção urinária de derivados de purinas (Aguiar et al., 2015; Rennó et al., 2008).

\section{Referências}

Aguiar, M.S.M.A.; Silva, F.F.; Donato, S.L.R.; Schio, A.R.; De Souza, D.D.; Meneses, M.A.; Lédo, A.A.; 2015. Síntese de proteína microbiana e concentração de ureia em novilhas leiteiras alimentadas com palma forrageira Opuntia. Semina: Ciências Agrárias, 36(2):999-1012. Doi: 10.5433/1679-0359.2015v36n2p999.

Association of Oficial Analytical Chemists - AOAC. 1995. Official methods of analysis. 16 ed. Washington: D.C.

Bal, M.A.; Büyükünal Bal, E.B. 2010. Interaction between particle sizes of alfalfa hay and corn grain on milk yield, milk composition, chewing activity, and ruminal pH of dairy cows. Turk J Vet Anim Sci, 34(1): 83-89. Doi: 10.3906/vet-0901-11.

Beigh, Y.A.; Ganai, A.M.; Ahmad, H.A. 2017. Prospects of complete feed system in ruminant feeding: A review. Veterinary Word, 10(4): 424-437. Doi: 10.14202/vetworld.2017.424-437.

Bürger, P.J.; Pereira, J.C.; Queiroz, A.C.; Silva, J.F.C.; Valadares Filho, S.C.; Cecon, P.R.; Casali, A.D.P. 2000. Comportamento ingestivo em bezerros holandeses alimentados com dietas contendo diferentes níveis de concentrado. Revista Brasileira de Zootecnia, 29(1): 236-242. Doi: 10.1590/S1516-35982000000100031.

Byskov, M.V.; Nadeau, E.B.E.; Johansson, O.; Norgaard, P. 2015. Variations in automatically recorded rumination time as explained by variations in intake of dietary fractions and milk production and between-cow variation. Journal of Dairy Science, 98: 3926-3937. Doi: 10.3168/jds.2014-8012.

Cochran, W.G. 1941. The distribution of the largest of a set of estimated variances as a fraction of their total. Annals of Human Genetics, 11(1): 47-52. Doi: 10.1111/j.1469-1809.1941.tb02271.x.

Dokovic, R.; Jasovic, B. 2010. Blood biochemical parameters and enzyme activity in beef cattle. Acta Agriculturae Serbica, 15(29): 47-54. Disponível em: https://scindeks-clanci.ceon.rs/data/pdf/03549542/2010/0354-95421029047D.pdf.

Dukes, H.H. 2006. Fisiologia dos Animais Domésticos. 12ª ed. Rio de Janeiro: Guanabara Koogan, 954p.

Figueiredo, M.R.P.; Saliba, E.O.S.; Borges, I.; Rebouças, G.M.N.; Aguiar e Silva, F.; Sá, H.C.M. 2013. Comportamento ingestivo de ovinos alimentados com diferentes fontes de fibra. Arq. Bras. Med. Vet. Zootec, 65(2): 485-489. Doi: 10.1590/S0102-09352013000200026.

\section{Conclusão}

A utilização de ração extrusada na alimentação de ovinos em diferentes relações V:C não compromete o consumo, comportamento ingestivo e perfil metabólico dos animais. Ovinos alimentados com estas dietas conseguem manter estáveis o metabolismo energético, proteico e mineral, sem desenvolvimento de problemas no fígado e rins.

\section{Aprovação do Comitê de Ética}

O projeto foi aprovado pela Comissão de Ética na Utilização de Animais (CEUA) da UFU sob o número $140 / 16$.
Gomes, S.P.; Borges, A.L.C.C.; Borges, I.; Macedo Júnior, G.L.; Silva, A.G.M.;Pancoti, C.G. 2012. Efeito do tamanho de partícula do volumoso e da frequência de alimentação sobre o consumo e a digestibilidade em ovinos. Revista Brasileira de Saúde e Produção Animal, 13(1): 137-149. Doi: 10.1590/S1519-99402012000100012.

González, F.H.D.; Scheffer, J.F.S. 2003. Perfil sanguíneo: ferramenta de análise clínica, metabólica e nutricional. In: I simpósio de patologia clínica veterinária da região sul do Brasil, 1 ed. Rio Grande do Sul, 73-88. Disponível em: https://lume.ufrgs.br/handle/10183/13177.

Johnson, T.R.; Combs, D.K. 1991. Effects of prepartum diet, inert rumen bulk, and dietary polyethylene glycol on dry matter intake of lactating dairy cows. Journal of. Dairy Science, 74(3): 933-944. Doi: 10.3168 / jds.S0022-0302 (91) 78243-X.

Kaneko, J.J.; Harvey, J.W.; Bruss, M.L. 2008. Clinical biochemistry of domestic animals.6 ${ }^{\underline{a}}$ ed. New York; Academic Press;928p.

Kleen, J.L.; Hooijer, G.A.; Rehage, J.; Noordhizen, J.P.T.M. 2003. Subacute ruminal acidosis (SARA): a review. Journal of veterinary medicine, 50:406-414. Doi: 10.1046/j.1439-0442.2003.00569.x.

Moharrery, A. 2010. Effect of Particle Size of Forage in the Dairy Ration on Feed Intake, Production Parameters and Quantification of Manure Index. Asian-Australian Journal of Animal Science, 23(4): 483-490. Doi: 10.5713/ajas.2010.90390.

National Research Council - NRC. 2007. Nutrient Requirements of Small Ruminants: Sheep, Goats, Cervids, and New World Camelids. Washington, DC: The National Academies Press.

Oetzel, G.R. 2017. Diagnosis and management of subacute ruminal acidosis in dairy herds. Vet Clin Food Animal, 33: 463-480. Doi: 10.1016/j.cvfa.2017.06.004.

Oliveira, K.A.; Macedo Junior, G.L.; Silva, S.P.; Araújo, C.M.; Varanis, L.F.M.; Sousa, L.F. 2018. Nutritional and metabolic parameters of sheep fed with extrused roughage in comparison with corn silage. Semina: Ciências Agrárias, 39(4): 1795-1804. Doi: 10.5433/1679-0359.2018v3 9n4p1795.

Rennó, L.N.; Valadares Filho, S.C.; Valadares, R.F.D.; Paulino, M.F.; Rennó, F.P.; Silva, P.A. 2008. Níveis de ureia na ração de novilhos de quatro grupos genéticos: estimativa da produção de proteína microbiana por meio dos derivados de purinas na urina utilizando duas metodologias de coleta. Revista Brasileira de Zootecnia, 37(3): 546-555. Doi: 10.1590/ S1516-35982008000300021. 
Ruela, P. A. C. et al.

Saeed, A.O.; Sazili, A.Q.; Akit, H.; Alimon, A.R.; Samsudin, A.A.B. 2018. Effect of corn supplementation on purine derivatives and rumen fermentation in sheep fed PKC and urea-treated rice straw. Tropical Animal Health Production. 50: 1859-1864. Doi: 10.1007 / s11250018-1636-1.

Salman, A.K.D. 2008. Utilização da amireia na alimentação de ruminantes. Embrapa Rondônia, 1:21. Disponível em: < https://ainfo. cnptia.embrapa.br/digital/bitstream/CPAF-RO-2010/13294/1/doc126amireia-.pdf.

Santos, R.P.; Sousa, L.F.; Sousa, J.T.L.; Andrade, M.E.B.; Macedo Junior, G.L.; Da Silva, S.P. 2015. Parâmetros sanguíneos de cordeiros em crescimento filhos de ovelhas suplementadas com níveis crescentes de propilenoglicol. Revista Brasileira de Ciências Agrárias, 10(3): 473 478. Doi: 10.5039/agraria.v10i3a4924.

Santos, T.C.P.; Alfaro, C.E.P.; Figueiredo, S.M. 2011. Aspectos sanitários e de manejo em criações de caprinos e ovinos na microrregião de patos, região semi-árida da Paraíba. Ciência Animal Brasileira. 12(2), 206212. Doi: 10.5216/cab.v12i2.4420.

Statistical Analysis System SAS. 2012. SAS Software. Version 9.4. Cary, North Carolina: SAS Institute Inc.

Seo, S.; Lanzas, C.; Tedeschi, L.O.; Pell, A.N.; Fox, D.G. 2009. Development of a mechanistic model to represent the dynamics of particle flow out of the rumen and to predict rate of passage of forage particles in dairy cattle. Journal of Dairy Science, 92: 3981-4000. Doi: 10.3168/jds.2006-799.
Shapiro, S.S.; Wilk, M.B. 1965. An Analysis of Variance Test for Normality, (Complete Samples). Biometrika, 52(3/4), 591-611. Doi: $10.2307 / 2333709$.

Silva, D.A.P.; Varanis, L.F.M.; Oliveira, K.A.; Sousa, L.M.; Siqueira, M.T.S.; Macedo Júnior, G.L. 2020. Parâmetros de metabólitos bioquímicos em ovinos criados no Brasil. Caderno de ciências agrárias, v. 12, p. 1-5. Doi: 10.35699/2447-6218.2020.20404.

Tedeschi, L.O.; Molle, G.; Menendez, H.M.; Cannas, A.; Fonseca, M.A. 2019. The assessment of supplementation requirements of grazing using nutrition models, 3(2): 812-828. Doi: 10.1093/tas/txy140.

Varanis, L. F. M. 2018. Prospecção de metabólitos sanguíneos referenciais para ovinos em distintas categorias. Uberlândia: Universidade Federal de Uberlândia, 90f. Dissertação Mestrado. Disponível em: https:// repositorio.ufu.br/handle/123456789/21703.

Vieira, J.S.; Logato, P.V.R.; Ribeiro, P.A.P.; Freitas, R.T.F.; Fialho, E.T. 2005. Efeito do processamento do milho sobre o desempenho e composição de carcaça de piaba (Leporinusfriderici) criada em tanques-rede. Ciência Agrotécnica, 29(2): 453-458. Doi: 10.1590/ S1413-70542005000200025.

White, R.R.; Hall, M.B.; Firkins, J.L.; Kononoff, P.J. 2017. Physically adjusted neutral detergente fiber system for lactating dairy cow rations. I: Deriving equations that identify factors that influence effectiveness of fiber. Journal of Dairy Science, 100: 9551-9568. Doi: 10.3168/ jds.2017-12766. 